\title{
Possible hafnium isotope evidence for continental emergence prior to 3.22 Ga
}

IAN FOSTER $^{1,2}$, PERRIN HAGGE ${ }^{3}$, HAYLEY BRICKER ${ }^{2}$, ARNAUD AGRANIER ${ }^{1}$, INGA KÖHLER ${ }^{4}$, MARTIN HOMANN $^{5}$, CHRISTOPH HEUBECK ${ }^{4}$, PHILIPPE NONNOTTE ${ }^{1}$, KURT KONHAUSER ${ }^{6}$, ARADHNA TRIPATI $^{1,2}$ AND STEFAN V. LALONDE ${ }^{1}$

${ }^{1}$ University Brest

${ }^{2}$ UCLA

${ }^{3}$ Princeton University

${ }^{4}$ Friedrich-Schiller-University Jena

${ }^{5}$ University College London

${ }^{6}$ University of Alberta

Presenting Author: perrin.hagge@gmail.com

The first terrestrial habitats would have developed coincident with the generation of continental crust and the emergence of continents. Associated with this critical Earth-Life transition would have been the initiation of substantial subaerial weathering. Recently, fluvial sediments and nitrogen isotopebased evidence for a terrestrial biosphere have been reported from the 3.2 billion year old Moodies Group. Here we report hafnium isotope values for marine banded iron formations from the same succession. Values observed are amongst the most extreme values reported. These data exhibit a systematic departure from the terrestrial array, and if primary, can be explained by transport and weathering of felsic minerals under subaerial conditions, with values comparable to modern Amazon river waters and acid leachates of granite. These data from marine sediments likely constitute the earliest geochemical evidence of subaerial weathering processes affecting oceanic chemistry. This would imply that continental crust was an ecological niche and source of nutrients by the time they formed, at 3.22 billion years ago at the end of the Paleoarchean, consistent with interpretations of terrestrial sediments from the same succession that indicate microbial life and biogeochemical cycling were present at this time. 